\title{
APORTACIÓN DE MÉXICO AL ARBITRAJE DE INVERSIÓN
}

\author{
Francisco GONZÁlEZ DE COSSÍO*
}

RESUMEN: Este estudio analiza la aportación de México al arbitraje de inversión. Para ello, se estudian los casos en los que México ha sido parte haciendo hincapié en las aristas legales recurrentes, la respuesta de los tribunales arbitrales al respecto, comentando dudas que han generado y las respuestas que al respecto se han presentado, para concluir con sugerencias sobre los pasos a seguir con respecto a esta área.

ABSTRACT: This paper analyzes Mexico's contribution to investment arbitration. To such end, a comment is made as regards the cases Mexico has been involved in, stressing the recurring issues as well as the answers thus far provided by tribunals. The questions raised and the answers provided are commented upon, in order to conclude with suggestions as regards the future course of action to address the same.

RÉSUMÉ: Cette étude analyse l'apport du Mexique en matière d'arbitrage de l'investissement. Pour cela, l'auteur étudie les affaires dans lesquelles le Mexique a été partie, soulignant les problèmes légaux récurrents, la réponse des tribunaux d'arbitrage. Il commente les doutes et les réponses dues à cette pratique professionnelle. Et proposenne des suggestions sur la marche à suivre dans cette matière.

* Maestría y doctorado por la Universidad de Chicago. Profesor de arbitraje, derecho mercantil y competencia económica. 
SUMARIO: I. Introducción. II. Los casos. III. Las cuestiones jurídicas involucradas. IV. Los argumentos en contra del arbitraje de inversión. V. Respuestas de México. VI. Comentario final.

\section{INTRODUCCIÓN}

En forma creciente, México se está convirtiendo en una de las fuentes más dinámicas y ricas de conocimiento y experiencia en materia de arbitraje de inversión. Este artículo identificará por qué con un resumen de los casos a la fecha resueltos (II); al mencionar los puntos legales que han involucrado (III); con el tratamiento de algunas de las dudas que ha generado (IV); y mediante la evaluación de algunas respuestas que ante ello se han generado (V).

\section{LOS CASOS}

A la fecha, México ha sido parte de doce casos. ${ }^{1}$ De los mismos, cinco han concluido, mismos que a continuación resumiré.

\section{Azinian}

En Robert Azinian and others $v$. United Mexican States ${ }^{2}$ los demandantes Robert Azinian, Kenneth Davitian y Ellen Baca iniciaron un procedimiento arbitral bajo el capítulo XI del Tratado de Libre Comercio para América del Norte (TLCAN) en contra de la terminación por el Mu-

1 Robert Azinian and others $v$. United Mexican States (Caso CIADI No. ARB(AF)/97/2); Metalclad Corporation $v$. United Mexican States (Caso CIADI No. ARB(AF)/97/1); Waste Management, Inc. $v$. United Mexican States (Caso CIADI No. ARB(AF)/98/2); Marvin Roy Feldman Karpa $v$. United Mexican States (Caso No. ARB(AF)/99/1); Técnicas Medioambientales Tecmed, S.A. $v$. United Mexican States (Caso No. ARB(AF)/00/2); Waste Management, Inc. $v$ United Mexican States (Caso CIADI No. ARB(AF)/00/3) Adams et al $v$. United Mexican States, (Notificación de Arbitraje presentada el 16 de febrero de 2001); Calmark Commercial Development Inc. and the United Mexican States (Notificación de Arbitraje de fecha 11 de enero de 2002); Corn Products International $v$. the United Mexican States (Notificación de Arbitraje de 2002; Fireman's Fund and the United Mexican States (Caso CIADI No. ARB(AF)/02/01); Frank and the United Mexican States (notificación de arbitraje del 5 de agosto de 2002); GAMI Investments, Inc. and the United Mexican States (Caso CIADI No. ARB(AF)/02/01); International Thunderbird Gaming Corporation $v$. the United Mexican States (arbitraje bajo el reglamento de arbitraje de la UNCITRAL iniciado en 1o de agosto de 2001). Esta información es vigente a junio de 2004.

2 Caso CIADI No. ARB(AF)/97/2, Laudo de fecha 1o de noviembre de1999. 
nicipio de Naucalpan de una concesión para la recolección y desecho de basura por la existencia de irregularidades. Los demandantes sostenían que la terminación constituía una violación a: (i) el deber mínimo de trato contenido en el artículo 1105 del TLCAN; y (ii) una expropiación en violación del artículo 1110 del TLCAN.

El tribunal rechazó ambas reclamaciones. Determinó que los demandantes no habían demostrado que la terminación de la concesión, que fue realizada con fundamento en dos causales legales distintas (invalidez y rescisión), pudiera generar responsabilidad internacional. Dado que la conducta del municipio fue validada por tribunales nacionales, el actuar de los tribunales mismos debía ser repudiado a nivel internacional para que la terminación de la concesión se tradujera en un ilícito internacional. Y esto no tuvo lugar. Las determinaciones fueron consideradas irreprochables. A su vez, dado que se determinó que no existía una violación del artículo 1110 del TLCAN, no existió una violación del artículo 1105.

La decisión es no sólo profunda, sino lectura obligatoria para cualquiera interesado en la denegación de justicia. No obstante que mucho podría decirse al respecto, me abstendré. Sin embargo, hago notar que proporciona un análisis interesante sobre las diferencias de niveles de escrutinio entre derecho y tribunales nacionales y derecho, y tribunales internacionales en materia de inversión internacional.

\section{Metalclad}

En Metalclad Corporation $v$. United Mexican States ${ }^{3}$ el demandante inició un procedimiento arbitral bajo el capítulo XI del TLCAN por el rechazo de un permiso de construcción por un Municipio del Estado de San Luis Potosí, emitido en las fases avanzadas de la construcción de un confinamiento de residuos peligrosos, por el cual Metalclad decía que había recibido seguridades gubernamentales sobre su obtención. Metalclad sostenía que dicha negación, en conjunción con las circunstancias de la misma y la emisión de un decreto ambiental que comprendía las instalaciones del confinamiento, prohibían de facto la utilización de la inversión, violando los requisitos de trato del TLCAN y compromisos sobre no-expropiación. 
El tribunal sostuvo que las obligaciones bajo el TLCAN fueron violadas en dos respectos: (1) El deber de México de dar a las inversiones de inversionistas un trato de conformidad con el derecho internacional, incluyendo trato justo y equitativo, de conformidad con el artículo 1105(1) del TLCAN; y (2) que México indirectamente expropió, sin compensación, la inversión de Metalclad. El rechazo del permiso de construcción, incluyendo la forma y el fundamento de conformidad con la cual se emitió, se determinó que fue el tipo de interferencias gubernamentales que tenían el efecto de privar al propietario de los beneficios económicos razonablemente esperados de la inversión, lo que constituía una medida equivalente a una expropiación en violación del artículo 1110 del TLCAN. Como un punto separado, el tribunal sostuvo que la forma en que el decreto ecológico fue implementado - que permanentemente proscribió el uso por Metalclad de su inversión-también constituyó una medida equivalente a una expropiación en violación al artículo 1110 del TLCAN. El tribunal otorgó a Metalclad una indemnización por daños y perjuicios por US\$16,685,000.00.

México inició un procedimiento de nulidad ante la Suprema Corte de British Columbia (la "Corte de BC") (Vancouver era la sede del arbitraje) reclamando que el Tribunal en Metalclad excedió su jurisdicción en dos respectos: (a) al utilizar las disposiciones sobre transparencia como el fundamento para determinar una violación al artículo 1105; y (b) al excederse en el ámbito de las disposiciones de transparencia contenidas en el TLCAN al haber creado nuevas obligaciones de transparencia. La Corte de $\mathrm{BC}$ determinó que el ámbito del laudo excedió el sometimiento al arbitraje (que estaba limitado a las fronteras del capítulo XI del TLCAN) y por ende parcialmente anuló el mismo. Al hacerlo, la Corte de $\mathrm{BC}$ consideró que, en la medida en que la misión de un Tribunal Arbitral del TLCAN está circunscrito al derecho contenido en el capítulo XI, al basarse en disposiciones ubicadas fuera de dicho universo (específicamente, el objetivo de transparencia ubicado en el capítulo I del TLCAN), el Tribunal Metalclad emitió un laudo ultra petita. En relación con la equiparación del decreto ecológico a una violación del artículo 1110 , dado que dicho concepto era independiente, y que el laudo no incluyó en sus premisas el análisis de transparencia, la Corte de BC sostuvo que era una determinación que resistía el análisis de nulidad. 


\section{Waste Management}

En Waste Management $v$. United Mexican States ${ }^{4}$ derivó de una inversión de Waste Management como parte de una concesión para la recolección y desecho de basura en Acapulco. El demandante sostenía que existía una conspiración entre las autoridades de los poderes Ejecutivo y Judicial del gobierno de Acapulco que constituía una violación de la obligación de trato mínimo del artículo 1105 del TLCAN. El demandante también argumentaba que la conducta de las autoridades de Acapulco equivalían a una medida equivalente a expropiación en violación del artículo 1110 del TLCAN, dada la imposibilidad de explotar la inversión. El tribunal rechazó ambas reclamaciones. Sostuvo que no existía evidencia de la supuesta conspiración, ni que el tratamiento al que el demandante había estado sujeto fuera arbitrario, injusto, imparcial o "idiosincrásico" (idiosyncratic) como el demandante lo calificaba. Tampoco había una violación al debido proceso por el hecho de que el Ayuntamiento de Acapulco incurría en tácticas dilatorias.

Dos aspectos adicionales merecen una nota independiente. En primer lugar, una diferenciación clara fue realizada entre violaciones-reclamaciones contractuales y reclamaciones bajo el TLCAN. En resumidas cuentas, una violación contractual por una entidad estatal no necesariamente se traduce en una violación al tratado. Son diferentes los estándares de revisión, lo cual es un tema que amerita un estudio independiente dada su importancia y profundidad. Una clarificación interesante y útil fue realizada, aunque en obiter: la protección bajo el capítulo XI del TLCAN no es un seguro de protección y no es la función del derecho internacional de las inversiones extranjeras eliminar los riesgos comerciales normales.

En segundo lugar, México sostenía que Waste Management carecía de locus standing como resultado de la existencia de una entidad-eslabón corporativo en Islas Caimán en la cadena corporativa entre el demandante y la inversión. El tribunal rechazó la excepción sosteniendo que el TLCAN no requería que la inversión misma tuviera la misma nacionalidad del inversionista que se beneficia de la protección a la inversión bajo el TLCAN. 


\section{Tecmed}

En Técnicas Medioambientales Tecmed $v$. Estados Unidos Mexicanos $^{5}$ el demandante comenzó un procedimiento arbitral bajo el Acuerdo para la Promoción y Protección Recíproca de Inversiones ente los Estados Unidos Mexicanos y el Reino de España (el APPRI) ${ }^{6}$ reclamando que su inversión, que consistió en un confinamiento de residuos peligrosos, había sido expropiada de facto como resultado de la negativa por el Instituto Nacional de Ecología (INE) a renovar la autorización para operar la Resolución. El demandante argumentaba que dicha omisión violaba diversas disposiciones del APPRI, incluyendo, inter alia, el deber de brindar un trato justo, nacional y más favorable a su inversión.

El tribunal sostuvo que (1) la resolución era (a) una medida equivalente a una expropiación, (b) que violaba el APPRI; (2) que la garantía de trato justo había sido violada; y (3) que la garantía de plena protección y seguridad había sido violada. El resto de las reclamaciones fueron rechazadas. El laudo hizo una condena por daños y perjuicios que ascendió a US\$5,533,017.12 más intereses a partir de noviembre de 1998.

La determinación del tribunal se basó en un análisis de "efectos": como resultado de la resolución se privó al demandante en forma radical, irreversible y permanente de la explotación de la inversión, como si los derechos a la misma hubieran cesado.

La medida equivalente a expropiación era violatoria del tratado puesto que las circunstancias fácticas que la motivaron no justificaban una medida tan drástica como la no-renovación de la autorización. Es decir, no existió proporcionalidad entre las circunstancias y la medida jurídica. Los hechos involucraron ciertas infracciones a la autorización inicial para operar que no podía razonablemente justificar la nulificación de los beneficios económicos de la inversión. El tribunal sostuvo que las verdaderas razones que motivaron la resolución eran los disturbios sociales que la inversión generaba.

5 Caso CIADI No. ARB(AF)/00/2, Laudo de fecha 29 de mayo de 2003.

6 Firmado el 22 de junio de 1995, el decreto aprobatorio del Senado fue publicado en el Diario Oficial de la Federación el 20 de diciembre de 1995, el decreto promulgatorio fue publicado en el Diario Oficial de la Federación el 19 de marzo de 1997, y entró en vigor el 18 de noviembre de 1996. 
El tribunal sostuvo que existió una violación al deber de dar un trato justo y equitativo como resultado de la incongruencia entre la motivación real detrás de la resolución y aquellas en las cuales se fundamentó el INE en la resolución. La falta de transparencia, claridad y precisión, así como la duplicidad de objetivos del INE, frustraron las justas expectativas en las cuales se basó el demandante y fueron consideradas contradictorias con el deber de dar un trato justo y equitativo contenido en el tratado.

El tribunal rechazó la reclamación de violación a la plena protección y seguridad determinando que no existía prueba alguna que las autoridades mexicanas habían incitado o participado en el movimiento social y político en contra del confinamiento de residuos peligrosos. Aunque en obiter dicta, el tribunal hizo interesantes comentarios sobre el alcance de dicha garantía: no impone responsabilidad objetiva al Estado huésped.

\section{Feldman}

En Marvin Feldman $v$. United Mexican States ${ }^{7}$ el demandante estadounidense Marvin Roy Feldman Karpa inició un procedimiento arbitral bajo el capítulo XI del TLCAN en contra de la negativa del México de reconocer el derecho a la devolución de impuestos especiales sobre producción y servicios (IEPS) derivados de la exportación de cigarros por CEMSA, la entidad mexicana de la que era accionista, reclamando que constituía una violación al deber de trato nacional contenido en el artículo 1102 del TLCAN, el deber de trato mínimo contenido en el artículo 1105 del TLCAN, y constituía una expropiación en contra del artículo 1110 del TLCAN.

El tribunal rechazó las reclamaciones de trato mínimo y expropiación, pero sostuvo la existencia de la discriminación.

La reclamación de violación al deber de trato mínimo contenida en el artículo 1105 fue rechazada en la medida en que es inaplicable a impuestos.

En relación con la reclamación de expropiación, el tribunal sostuvo que las circunstancias no constituían una expropiación ni una medida equivalente a la misma. Consideró que existían diversos factores que militaban en contra de una determinación sobre la existencia de una expropiación, particularmente que el negocio de exportación de cigarros per- 
manecía bajo el control del demandante. Otros criterios fueron que no todos los problemas de negocios podían traducirse en una expropiación y que las leyes fiscales mexicanas no le daban el derecho a CEMSA a obtener las devoluciones de la exportación de los cigarros, sino sólo el derecho a la aplicación de una tasa del $0 \%$. No obstante que se determinó la existencia de inconsistencias y arbitrariedades en la conducta de las autoridades fiscales, no llegaron a niveles de una apropiación o taking, como se denomina en el argot estadounidense.

En relación con la reclamación de violación de trato nacional, el tribunal sostuvo que México había violado los derechos del demandante a no ser discriminado (de conformidad con el artículo 1103 del TLCAN) ya que le permitió a un revendedor local (el Grupo Poblano) la oportunidad de hacer dichas devoluciones, mientras las negaba a CEMSA.

El tribunal emitió un laudo condenando al pago de $\$ 9,464,627.50$ pesos más intereses.

\section{LAS CUESTIONES JURÍDICAS INVOLUCRADAS}

Como seguramente ha observado el lector, las cuestiones jurídicas más recurrentes han sido: 1) El deber de dar un trato justo y equitativo; y 2) Expropiación (y medidas equivalentes a la misma). Esto no debe sorprender. Después de todo, se trata de los temas más debatidos en la rama del derecho internacional de las inversiones extranjeras (un cuerpo legal caracterizado por puntos de vista agudamente opuestos y atrincherados). A continuación comentaré brevemente sobre cada uno.

\section{Trato mínimo}

El artículo 1105(1) del TLCAN establece que: "1. Cada una de las partes otorgará a las inversiones de los inversionistas de otra parte, trato acorde con el derecho internacional, incluido trato justo y equitativo, así como protección y seguridad plenas".

Otros tratados de inversión contienen textos substancialmente similares (si no es que idénticos).

Dicho texto es el producto de un periodo largo de experiencias a las cuales México ha contribuido en forma importante. La contribución de México ha sido histórica y contemporánea, y no sólo se relaciona con el texto actual, sino también con su contenido, interpretación y aplicación. 
Para comenzar con experiencias históricas, dos casos que han involucrado a México son rutinariamente citados como importantes fuentes legales de orientación sobre el nivel de trato que cae dentro de los estándares internacionalmente aceptados: Neer y Roberts. Ambos casos son producto de la Comisión de Reclamaciones México-Estados Unidos establecida en 1924 con la finalidad de resolver reclamaciones que derivaban de la revolución mexicana. Sucintamente, Neer 8 involucró el asesinato de un ciudadano estadounidense (Neer) que era superintendente de una mina en México por un grupo de hombres (no afiliados al gobierno) en camino a su casa después del trabajo. Roberts ${ }^{9}$ versó sobre el tratamiento de un ciudadano estadounidense (Roberts) que fue arrestado por lesiones y encarcelado durante 19 meses en una cárcel pequeña, saturada, sin comodidad ni mueble alguno, carente de sanitarios, y en donde la comida era escasa, sucia y soez.

Estos casos son frecuentemente citados en fuentes autoritativas como ejemplos del tipo de conducta atribuible al Estado que genera responsabilidad internacional por ser violatoria al deber de brindar trato conforme a estándares mínimos. Fundamentan la proposición (genérica) que un Estado le debe a extranjeros plena protección y seguridad. El que éste estándar incluya "trato justo y equitativo" parece ser de una cosecha más reciente, pero (que tenga conocimiento) no ha sido cuestionado el que forme parte de dicho estándar.

Suficiente historia. En relación con la interpretación contemporánea del contenido de lo que constituye "tratamiento acorde con derecho internacional, incluyendo trato justo y equitativo y seguridad y protección plena", México también ha proporcionado experiencia. Los casos resumidos en el epígrafe II de este comentario dan contenido a éste abstracto estándar.

En lugar de resumir cuál es dicho contenido (lo cual ameritaría un estudio independiente, so pena de ser tildado de simplista), tan sólo comentaré sobre la importancia de dicha labor, particularmente por el perfil de las autoridades a las que va dirigidas. Por las razones detalladas en el epígrafe IV, 3 de este estudio, dar contenido a lo que significa "trato acorde con derecho internacional, incluyendo trato justo y equitativo y 
plena protección y seguridad" es de importancia capital para las autoridades mexicanas.

\section{Expropiación}

El artículo 1110(1) del TLCAN establece que:

\section{Artículo 1110. Expropiación e indemnización}

1. Ninguna de las Partes podrá nacionalizar ni expropiar, directa o indirectamente, una inversión de un inversionista de otra Parte en su territorio, ni adoptar ninguna medida equivalente a la expropiación o nacionalización de esa inversión (expropiación), salvo que sea:

a) Por causa de utilidad pública;

b) Sobre bases no discriminatorias;

c) Con apego al principio de legalidad y al artículo 1105(1); y

d) Mediante indemnización conforme a los párrafos 2 a 6 .

La expropiación ha sido desde hace tiempo el dolor de cabeza del derecho internacional de las inversiones extranjeras. La redacción de éste artículo podría, en forma resumida, ser considerada como la síntesis de dos especies de dicho género: (i) expropiación directa; y (ii) expropiación indirecta. Mientras que la primera se refiere a los actos de Estado que son claramente expropiaciones (actos que transfieren la propiedad de activos), las segundas ("medidas equivalentes a expropiación") se refieren a otras actividades que afectan la propiedad privada y que pueden (o no) transferir los derechos de propiedad o interferir en forma no-razonable con el uso, goce y explotación de derechos de propiedad. Estos actos pueden involucrar impuestos, regulación o demás actos que no se refieran a regulación o imposición de impuestos de buena fe, o demás conducta estatal que forme parte de las facultades de policía de un Estado. Estas han sido en ocasiones 'eufemísticamente' bautizadas como "creeping expropriation".

Un lector letrado en ésta área seguramente sujetaría mi descripción anterior a matices o refinaciones. Son bienvenidas. No sólo porque mi descripción es un resumen, sino también porque toda el área está sujeta a controversia. No abundaré sobre la misma más que para comentar sobre los casos que a la fecha han involucrado a México: los tribunales que han conocido de estos temas no han centrado su análisis en la forma, método o denominación de las medidas que pueden ser equivalentes a expropia- 
ción. Más bien, se han enfocado en el resultado: si ha existido una transferencia de propiedad, o si la inversión fue tan afectada que el inversionista no pueda funcionalmente obtener los beneficios de la misma. Dicho de otra manera, los tribunales generalmente hacen un "análisis de los efectos" ("effects test") para considerar si están en presencia de una "medida equivalente a expropiación".

\section{LOS ARGUMENTOS EN CONTRA DEL ARBITRAJE DE INVERSIÓN}

El arbitraje de inversión ha atraído mucha atención no sólo de la academia, sino también de los frentes políticos y civiles. México no es una excepción. En esta nota abordaré únicamente los cuestionamientos serios que se han presentado, haciendo caso omiso de la diatriba atávica que, si bien abundante, es en gran medida auto-destructiva.

Me he encontrado con dos argumentos que merecen ser sondeados: (1) si el arbitraje de inversión compromete la soberanía nacional; y (2) la incertidumbre derivada de la posibilidad de que el derecho internacional pueda ser violado no obstante el acatamiento del derecho local.

\section{Violación a la soberanía}

Se ha sostenido que el juzgamiento por tribunales arbitrales de actos de Estado constituye una violación a la soberanía nacional. En mi opinión, la preocupación es infundada puesto que: A. La soberanía, correctamente entendida, no implica libertad de hacer lo que el gobierno quiera, sino libertad de hacer lo que el derecho le autoriza; y B. Es en ejercicio de la soberanía que existe el arbitraje de inversión. Me explicaré.

\section{A. La soberanía no significa libertad irrestricta}

Tradicionalmente, la soberanía, que ha sido definida como la negación a toda subordinación o limitación del Estado por cualquier otro poder, ${ }^{10}$ se compone de dos nociones: independencia y supremacía. La independencia mira hacia el exterior. Se entiende cuando se aprecia en la forma en la que un Estado convive con otros miembros de la comunidad 
internacional. De esta manera, implica que el Estado se mueve en un plano de igualdad frente a los otros Estados. La supremacía mira hacia el interior. Implica la potestad que el Estado ejerce sobre los individuos y las colectividades dentro de su órbita. Es decir, mientras que la soberanía hacía dentro es superlativa, hacia fuera es igualitaria.

Desde la perspectiva internacionalista, la soberanía es independencia. Dicha independencia se externa con respecto a la libertad de acción fuera de sus fronteras, y es interna con respecto a la libertad de acción de un Estado dentro de sus fronteras. La independencia y la autoridad territorial y personal son los tres aspectos principales de la soberanía. ${ }^{11}$

La explicación anterior parecería cimentar, más que refutar, la observación que estoy en vías de comentar. Sin embargo, al profundizar sobre ello el lector percibirá el error conceptual.

La soberanía no implica ausencia de límites. Todo lo contrario, es en ejercicio de la soberanía que un pueblo se autolimita mediante la creación de un régimen constitucional que, además de establecer las funciones de un gobierno y dar las atribuciones del mismo, toma un paso adicional que es crucial: establece las limitantes del mismo.

La importancia de limitar el ejercicio de las funciones de un gobierno radica en que se establecen las bases con fundamento en las cuales se podrá encausar o, de ser necesario, detener el poder público que a través de las mismas una autoridad ejerce. ${ }^{12}$ De lo contrario, el ejercicio del poder público haría de los gobernados víctimas seguras del poder que estos últimos atribuyeron a la clase gobernante.

El que un Estado sea, como resultado de su soberanía, supremo dentro de su territorio no significa que tiene la habilidad de actuar en la forma que quiera. De hecho, la libertad, correctamente entendida, nunca implica el derecho a hacer lo que su titular desee, sino el derecho a escoger entre las opciones lícitas. De lo contrario, la libertad degeneraría en libertinaje.

Lo anterior es cierto tanto desde la perspectiva interna ${ }^{13}$ como internacional. Sobre esta última, existen ciertos pasajes en la famosa obra 
Oppenheim's International Law que no sólo son relevantes, sino elocuentes: ${ }^{14}$

La independencia no es la libertad ilimitada de un Estado para hacer lo que quiera. El hecho que un Estado sea un miembro de la comunidad internacional restringe su libertad de acción como resultado de las diversas reglas del derecho internacional consuetudinario que lo vinculan y como resultado de las diversas obligaciones derivadas de tratados que le afectan en la administración de sus asuntos internacionales. ${ }^{15}$

En otra parte, la misma obra continúa aclarando que:

Como consecuencia de su independencia interna y autoridad territorial, un Estado puede adoptar cualquier constitución que desee, manejar su administración en la forma que lo considere apropiado, adoptar las leyes que quiera, organizar sus fuerzas armadas en tierra y mar, construir y destruir instalaciones militares, adoptar cualquier política comercial que desee, etcétera - sujeto siempre, evidentemente, a las restricciones impuestas por el derecho consuetudinario internacional o por los tratados que le vinculan. ${ }^{16}$

En forma conclusiva, "como la independencia, la supremacía territorial no establece libertad ilimitada..." ("Like independence, territorial supremacy does not give unlimited liberty of action..."). ${ }^{17}$

Como puede verse, la soberanía, si bien implica que un pueblo puede hacer de sí mismo lo que quiera, no implica que el gobierno puede hacer lo que quiera. La observación parece banal, ${ }^{18}$ pero invito al lector

14 Oppenheim's International Law, cit., p. 390.

15 Citas omitidas y énfasis añadido. El texto en inglés dice: "Independence is not unlimited liberty for a state to do what it likes. The fact that a state is a member of the international community restricts its liberty of action, because of many rules of customary international law binding upon it and because of the many treaty obligations which affect it in the management of its international affairs."

16 Oppenheim's International Law, cit., pp. 383-384. El texto en ingles dice: "In consequence of its internal independence and territorial authority, a state can adopt any constitution it likes, arrange its administration in any way it thinks fit, enact such laws as it pleases, organize its forces on land and sea, build and pull down military installations, adopt any commercial policy it likes, and so on - subject always, of course, to restrictions imposed by rules of customary international law or by treaties binding upon it-".

17 Oppenheim's International Law, cit., p. 391.

18 Es interesante hacer notar una paradoja. Curiosamente, muchas afirmaciones profundas de diversas ciencias parecen, a primera vista, dar la apariencia de exactamente lo contrario: superficialidad. Sin embargo, vencida esa primera apariencia, y resistida la tentación de quedarse 
a que reflexione sobre la misma. Al hacerlo, se dará cuenta que adopta una noción aristotélica de la libertad: la libertad no es la facultad de hacer lo que uno desee; es la facultad de hacer lo que uno desee dentro el margen de acción de lo correcto, o, tomando una postura un poco más legalista, de lo lícito. Es decir, la libertad no es la facultad de optar por conducta vedada. Ello no es libertad, sino un abuso de la misma; es libertinaje.

Atemos tanto la noción interna como internacional de soberanía. Internamente, la soberanía implica supremacía sobre los suyos y su territorio; pero, dado que el ejercicio de la misma debe ser acorde con los requisitos que, como resultado de la autolimitación, estableció el constituyente, bajo el ejercicio de la misma no puede justificarse conducta que deje de observar dichas limitantes.

Internacionalmente, la igualdad con la que se maneja el Estado implica que otros miembros de la comunidad internacional no deben ejercer poder sobre el mismo; deben respetarlo como par.

Entendido lo que en verdad busca resguardar la soberanía, ¿cómo puede entenderse que los tribunales arbitrales violen la misma? La misión de estos tribunales es exclusivamente identificar si el ejercicio de una facultad transgrede o no una norma que el Estado libremente se comprometió a cumplir. Un Estado no pierde margen de acción por las determinaciones de un tribunal arbitral, ni se ejerce presión alguna para que un gobierno adopte un curso de acción distinto al que preferiría tomar. Lo único que se hace mediante el arbitraje de inversión es poner en manos de un mecanismo totalmente neutral la determinación de si un Estado ha cumplido con lo que se comprometió a cumplir.

Desde Hobbes (en Leviatán) ha sido comúnmente aceptado que una de las funciones del Estado es proteger a sus integrantes de depredadores, incluyendo el Estado mismo. En arbitraje de inversión no es más que un mecanismo más para realizar dicha función.

La soberanía, que es tan frecuentemente citada por países latinoamericanos, es —en este contexto - citada para la conclusión equivocada. De hecho, es como resultado de la soberanía que existe el arbitraje de inversión, como ahora explicaré. 


\section{B. El arbitraje de inversión es producto de un acto soberano}

El arbitraje de inversión es el mecanismo que los Estados que buscan atraer inversión extranjera utilizan con la finalidad de darle credibilidad a la promesa que, mediante los tratados de inversión, han realizado a la comunidad internacional. En ausencia de dicho mecanismo, la duda que siempre subsistiría en las mentes de inversionistas potenciales es: ¿cómo puedo confiar en que éste Estado huésped cumplirá con las promesas realizadas mediante el tratado de inversión?

Uno podría contestar: mediante tribunales nacionales. Sin embargo, esta respuesta sería el equivalente (a los ojos del inversor) de decir "usted sabe que cumpliré mis promesas-obligaciones puesto que así lo digo", un argumento que nunca ha sido muy exitoso.

El arbitraje de inversión es el producto de soberanía simplemente puesto que deriva de un acto de Estado: un tratado.

Este simple (posiblemente obvio) hecho es descuidado por los proponentes de la teoría que el arbitraje de inversión viola la soberanía nacional. ¿Debemos darle crédito a un argumento que postula que un Estado pierde soberanía cuando es forzado a cumplir con sus promesas (hechas para atraer inversión extranjera)? Es decir, ¿por su necesidad de cumplir con pacta sunt servanda? Francamente creo que no.

Los tratados de inversión son mecanismos para atraer inversión. Para lograr dicha finalidad, los Estados parte de los mismos hacen una serie de promesas a la comunidad de inversionistas internacionales que tienen por objetivo incrementar el atractivo de una jurisdicción como posible lugar de negocios.

Para entender por qué, invito al lector a que se ponga en los zapatos del director de Finanzas de una sociedad trasnacional o de un fondo de inversión que debe decidir dónde colocar recursos que le han sido confiados. Entre los elementos que el financiero en cuestión aquilatará está no sólo el retorno que puede obtener de cierta inversión, sino el riesgo involucrado. Analizará las diversas oportunidades de negocios en diversos mercados (jurisdicciones) del mundo. Es posible que existan proyectos atractivos en, por ejemplo, tres jurisdicciones: Colombia, Indonesia y México. Las tres ofrecen una posibilidad interesante de retorno a la inversión, pero sólo puede (o debe) invertir en una. Luego procederá a determinar el riesgo involucrado. Al hacerlo, tomará en cuenta, entre otros 
factores, el riesgo político ${ }^{19}$ de dicho mercado y la existencia de otras garantías que le brinden seguridad no sólo al principal invertido, sino también a la repatriación de utilidades de la misma. Dado que los tres países están "compitiendo" por dicha inversión, necesariamente serán comparados. El ejercicio de comparación no sólo analizará factores sociales, políticos y económicos, sino también jurídicos: la existencia de mecanismos creíbles para ventilar problemas que surjan. Téngase en cuenta que se trata de una jurisdicción foránea, por lo que el acceso a una infraestructura imparcial en donde se puedan ventilar las controversias que puedan surgir de la inversión se preferirá a simplemente contar con los mecanismos legales internos para atacar los actos de Estado, máxime que los órganos ante quienes se tendrían que enderezar los recursos legales son parte del Estado contra quien se entablarían. Por ello, aún asumiendo que fueran en verdad imparciales, ${ }^{20}$ es preferible — por apariencia de neutralidad - contar con el recurso adicional de acudir al mecanismo neutral.

Es en esta coyuntura en que cobran importancia los tratados de inversión. Estos instrumentos logran justamente estos objetivos. Los resultados han sido palpables. Los inversionistas extranjeros prefieren acudir a jurisdicciones que les proporcionan estos derechos adicionales. Como prueba de ello, me refiero a la enorme propagación de estos instrumentos a nivel mundial, ${ }^{21}$ así como el incremento en las inversiones que en nuestra economía ha tenido lugar desde la entrada en vigor del TLCAN, y los demás tratados de inversión que México ha celebrado.

Entendida la utilidad económica y práctica de estos instrumentos, vale la pena tocar el punto fundamental que deseo soslayar en esta sec-

19 El "riesgo político" también conocido como "Country-Risk Analysis", implica mucho más que el sistema político de un país. Abarca toda aquella circunstancia que influya sobre el 'clima' político y el mercado de un país que pueda ser relevante para efectos de una inversión e incluye, pero no esta limitado a, lo siguiente: el marco jurídico, el acatamiento de las leyes, aspectos sociales y económicos, las existencia de diferencias de idioma, étnicas y religiosas que puedan restarle estabilidad a un país, movimientos nacionalistas extremos, movimientos xenófobos que puedan dar pie a preferencias en el trato de extranjeros frente a nacionales, condiciones sociales desfavorables (incluyendo polarización social), conflictos sociales como lo pueden ser manifestaciones frecuentes, violencia, la existencia de guerrillas, la fuerza y organización de grupos radicales, la existencia de deuda extranjera, las reservas internacionales, crecimiento económico, exportaciones, etc. Véase Husted, Steven y Melvin, Michael, International Economics, 4a. ed., Addison-Wesley, 1998, pp. 527-531.

20 Algo que la experiencia internacional ha demostrado que con frecuencia no ocurre.

21 El número de tratados de inversión depositados ante las Naciones Unidas excede de dos mil. 
ción: el mecanismo a través del cual se manifiestan estas promesas para atraer la inversión son actos soberanos: la celebración de tratados internacionales.

El contenido de estos actos soberanos es, visto constitucionalmente, el establecimiento de normas que autolimitan el actuar de autoridades mexicanas a cumplir con las garantías de seguridad jurídica que contienen los mismos. Estas garantías incluyen, por lo general, el trato a la inversión, obligación de no discriminación, la promesa de no expropiar sin el pago de una compensación a valor de mercado, y el compromiso que cualquier duda sobre el cumplimiento de las mismas será ventilado, a elección del inversionista, ante las instituciones legales nacionales o ante un tribunal arbitral. La misión del tribunal arbitral no será otra que decidir si se observaron las promesas realizadas por el Estado huésped en relación con la inversión. Nada más, y nada menos. Luego entonces, es en cumplimiento con el acto soberano de comprometerse contractual e internacionalmente que un tribunal arbitral actúa. El procedimiento arbitral y la resolución (laudo) que a ello recaiga, no será más que el resultado del deseo del Estado de atraer inversión mediante promesas y el principio pacta sunt servanda. Por consiguiente, las supuestas "limitantes a la soberanía" que derivarán de un tratado de inversión son el producto de la soberanía misma. Como se explica en Oppenheim's International Law: "existen diversas obligaciones que un Estado puede asumir mediante tratados, sin por ello perder su independencia interna ni supremacía territorial... probablemente no existe Estado alguno que de alguna manera $\mathrm{u}$ otra no haya restringido su supremacía territorial mediante tratados con otros Estados". ${ }^{22}$

Si se acepta que la soberanía implica la libertad de un Estado de contratar internacionalmente, y que los pactos deben cumplirse, necesariamente se concluye que los procedimientos arbitrales son el resultado del ejercicio de la facultad soberana de entablar relaciones jurídicas internacionales. Su validez tanto desde la perspectiva interna como internacional queda entonces resguardada.

22 Oppenheim's International Law, cit., pp. 392 y 393. El texto anterior es una traducción del autor. El original en inglés dice: "there are many obligations which a state can assume through treaties, without thereby losing its internal independence and territorial supremacy... there is probably no state which is not in one point or another restricted in its territorial supremacy by treaties with other states". 


\section{Violación del derecho internacional no obstante el cumplimiento con derecho nacional}

Este fenómeno ha inquietado a muchos, particularmente a autoridades. Después de todo, puede ser desconcertante que una autoridad local, que ha cumplido con todos los requisitos que le son aplicables bajo derecho nacional, pueda estar violando derecho internacional. Sin embargo, la preocupación carece de mérito.

Es cierto. Es jurídicamente posible que un acto de autoridad sea lícito bajo derecho mexicano y aún así incumpla con lo dispuesto en los tratados de inversión. Sin embargo, no considero que ello sea intolerable, sino plausible.

Desde los primeros casos en los que México fue parte se detectaba que los tribunales arbitrales valoraban la conducta que suscitaba la reclamación de inversores bajo un estándar adicional a su sola legalidad bajo derecho mexicano. Dicha corriente de opinión se cristalizó en el caso Tecmed. El párrafo 120 del laudo final contiene dicha noción. Cito el párrafo 119 para no sacarlo de contexto:

119. Es principio indiscutido que el ejercicio por el Estado de facultades soberanas bajo el poder de policía puede ocasionar perjuicios económicos a los administrados sin compensación alguna. También lo es que en el ámbito o desde la perspectiva del derecho interno de ese Estado, es sólo conforme a su derecho y ante sus tribunales que deberán apreciarse en que medida el ejercicio de tales facultades es o no legítimo; y cuales son los límites que, de ser transgredidos, originan la obligación de indemnizar al administrado por violación de su derecho de propiedad.

120. Sin embargo, la perspectiva de este Tribunal Arbitral es distinta. Su función es la de examinar si la Resolución infringe el Acuerdo a la luz de las disposiciones y del derecho internacional. No revisa los fundamentos o las motivaciones que condujeron a la Resolución, a los efectos de determinar si fue o no legalmente expedida su procedencia. Pero sí debe considerar dichos aspectos para determinar si el Acuerdo fue o no violado. Que la actuación atribuible a la Demandada sea legítima, lícita o conforme a derecho desde la óptica de su derecho interno no significa que lo sea bajo el Acuerdo o el derecho internacional [citas omitidas y énfasis añadido].

Es la oración subrayada la que ha llamado la atención. En mi opinión, ¡debería ser labrada en piedra! Lo anterior por varias razones. 
En primer lugar, manifiesta un correcto entendimiento del estándar de revisión del tribunal arbitral. En segundo, puede anotarse como una victoria de los internacionalistas que durante tanto tiempo han procurado hacer valer la noción que el derecho internacional constituye un cuerpo legal adicional que el Estado debe acatar, so pena de convertir su derecho en un instrumento de autoritarismo. Abundaré al respecto.

La misión de un tribunal arbitral constituido de conformidad con un tratado de inversión es verificar si las normas contenidas en un tratado de inversión han sido acatadas en un caso particular. Nada más, nada menos. En la realización de dicho deber puede ser relevante el acatamiento de derecho local, pero también puede ser perfectamente irrelevante. El motivo es sencillo: se trata de un estándar de revisión distinto al de derecho local. Por ello, la generación de responsabilidad bajo derecho internacional puede incluir en su ecuación determinaciones de derecho local, o puede hacer caso omiso de las mimas.

La aseveración anterior, que puede parecer evidente a un abogado internacionalista, ha probado ser intolerable para muchos. Sin embargo, correctamente entendida, no difiere de la forma en que otras ramas del derecho (y tribunales nacionales) operan. Un hecho puede impactar diversas áreas jurídicas, y será el juez (o árbitro) competente bajo cada uno de dichos cuerpos legales quien lleve a cabo el análisis correspondiente en forma independiente. ${ }^{23}$ Por alguna razón, el hecho que uno de dichos

23 Pondré algunos ejemplos: el incumplimiento de un contrato puede tener implicaciones civiles (que serán determinadas por un juez de lo civil), mercantiles (que podrían ser ventiladas por un tribunal arbitral o un juez mediante un procedimiento ordinario mercantil), cambiarias (por involucrar un pagaré y serían ventiladas por el juez competente de conformidad con la Ley General de Títulos y Operaciones de Crédito), e implicar el desplazamiento de un competidor, y por ende posiblemente suscitar aspecto de competencia económica-lo cual determinaría la Comisión Federal de Competencia. Otro ejemplo más sencillo puede ser un accidente que pueda generar responsabilidad civil (reparación del daño) y penal (lesiones); o una desviación de recursos que puede implicar consecuencias civiles (nulidad del acto, responsabilidad por hecho ilícito, enriquecimiento sin causa), penales (abuso de confianza, fraude o peculado) y mercantiles (acción de responsabilidad), etcétera. Los ejemplos son infinitos. El fenómeno anterior obedece a una misma razón: el mismo acto generará aristas legales bajo diferentes cuerpos normativos. Cada uno que cuenta con un órgano aplicador del derecho distinto (sea juez penal, tribunal arbitral) que juzgará bajo el estándar de revisión contenido en el derecho aplicable, la generación (o no) de responsabilidad legal bajo dicho cuerpo. ¿Qué hay de diferente con el arbitraje de inversión? El que un acto de autoridad sea lícito bajo una legislación administrativa de un Estado (por ejemplo, una expropiación cuya indemnización sea el valor catastral), puede incumplir con la promesa de un tratado de inversión (que la compensación no sea inferior a valor de mercado). ¿Porqué extraña esto? 
ordenamientos sea derecho internacional y que el "juez" sea un árbitro, ha generado crítica. Considero que es infundada.

Como no deseo reducir la complejidad de la interrogante para dar la apariencia de que es evidentemente infundada, ${ }^{24}$ la defenderé por un momento. Posiblemente la preocupación resida en que dicha teoría puede situar a una autoridad en la desafortunada situación de no saber a qué atenerse al momento de actuar puesto que no sabe cómo vislumbrarán, ex post facto, los miembros de un tribunal arbitral la conducta en cuestión, máxime que la aquilatarán a la luz de principios abstractos contenidos en un tratado internacional que, dada la cantidad de los que existen-y que promete crecer - es posible que la autoridad no conozca. Entendida de esta manera, la postura tiene un punto interesante, que a continuación abordaré.

Es cierto que los principios internacionales contenidos en los tratados de inversión son abstractos. También es cierto que ya son muchos los tratados y es fácil que no se conozcan en su totalidad por las autoridades, y es casi seguro que no sabrán, a priori, cómo los concebirán o el contenido que les darán tribunales internacionales. Sin embargo, considero que ninguna de las preocupaciones es lo suficientemente válida para desvirtuar el mecanismo.

Sobre la abstracción vale la pena hacer tres observaciones. Lo abstracto de las normas obedece a que se está en presencia de una de las áreas más espinosas del derecho internacional, cuyo contenido ha sido intensamente debatido, por lo que la solución jurídica que se les ha dado es establecer un "estándar" que tome en cuenta las circunstancias del caso. ${ }^{25}$ En segundo lugar, lo abstracto (e inclusive extraño) que pueden parecer dichas normas obedece a que se esta utilizando una técnica jurídica distinta a la que se acostumbra en México: la reglamentación vía estándar, a diferencia de reglamentación vía regla — que es el más utilizado

24 Una técnica frecuentemente utilizada en la argumentación y que se le conoce como el "Strawman" (el espanta-pájaros). La técnica consiste en reducir la complejidad o solidez de un argumento a un aspecto sencillo (casi absurdo) para luego proceder a realizar la fácil tarea de desvirtuarlo (de allí la utilización de "strawman": es más fácil ganarle a un espanta-pájaros que a un contrincante verdadero). No me interesa incurrir en dicha falaz y deshonesta manera de argumentar.

25 Sobre los motivos de porqué el derecho internacional de las inversiones extranjeras es tan controvertido, puede acudirse el capítulo VIII sobre arbitraje de inversión en la obra Arbitraje, de Francisco González de Cossío, Porrúa, 2004. 
en México. ${ }^{26}$ Por lo general, en los sistemas jurídicos civilistas se acude al segundo tipo de regulación, mientras que el primer tipo de regulación es aquella preferida por sistemas consuetudinarios (del common law). Ambos sistemas pueden ser utilizados y tienen ventajas y desventajas. Si bien no abundaré sobre las mismas, mencionaré que, mientras que la regla da más certeza, el estándar es más flexible y con frecuencia más útil para llegar a un resultado justo o apropiado. Sin embargo, exige más del jugador.

En tercer lugar, invito al lector a que considere el contenido que se le ha dado a las normas en cuestión. Las reglas que pueden derivarse de los casos que a la fecha se han seguido, y que son relevantes en esta discusión, son que un acto de autoridad que cumple con derecho local, violará el deber de trato justo y equitativo si su sanción no es proporcional a la conducta que lo motiva.

¿Debe preocupar dicha interpretación del contenido de las normas de los tratados de inversión?, ¿Qué hay de malo con que, además de ser lícito, el acto de autoridad sea justo, o proporcional, o transparente?

Invertiría la pregunta a quien con base en lo anterior pone a los tratados de inversión en tela de juicio: ¿en verdad nos molesta comprometernos a que nuestras autoridades no tratarán en forma justa y equitativa a una inversión?, ¿es cuestionable la interpretación que los actos de autoridad que sancionen debe ser proporcionales a las omisiones que en inversionista incurrió?

Considero que la respuesta objetiva a todas las preguntas anteriores es negativa.

\section{Mediante el arbitraje de inversión se juzga a las autoridades}

mexicanas bajo un estándar distinto

del que están acostumbrados

Existe otra fuente seria de preocupación del arbitraje de inversión que, si bien no he escuchado a nadie decir, posiblemente esté en proceso de gestación, o es el aspecto que aún no se articula por aquellos críticos de la institución cuando dicen que hay "algo" mal con la misma: el estándar de revisión bajo el cual se juzga conducta gubernamental bajo

26 Aunque la tendencia en nuestro sistema jurídico es reglamentar vía regla, existen algunas normas que adoptan estándares. Por ejemplo, el estándar de "buen padre de familia" contenido en el artículo 391 de la Ley General de Títulos y Operaciones de Crédito. 
tratados de inversión difiere del derecho originalmente aplicable, no sólo en cuanto a contenido sino también en método. Me explicaré.

México sigue un sistema de tradición civilista y, en su mayoría, involucra un sistema de legislación por reglas. Lo anterior implica que, en general, el derecho mexicano está compuesto por reglas y no por estándares. Las autoridades mexicanas están acostumbradas a saber cuáles son sus facultades y poderes, así como su alcance, mediante la revisión de cuerpos legislativos que detallan con bastante precisión no sólo qué deben hacer, sino también cómo hacerlo. Saben que si siguen dichas reglas, su conducta no será tildada de inválida (o inconstitucional).

Las autoridades mexicanas no están acostumbradas a estándares. Cuando observan derecho basado en estándares sienten que no se proporcionan suficientes lineamientos sobre el nivel de escrutinio al cual se someterán sus actos. Esto es en contraste con otros sistemas, notoriamente el consuetudinario (common law) y el internacional. Por consiguiente, esta divergencia constituye una fuente de tensión, confusión y crítica que es válida, por lo menos desde la perspectiva de estas autoridades.

Desde la perspectiva de las autoridades mexicanas, dada la ambigüedad de estándares y diferencia de método, qué puede constituir una violación a un tratado de inversión es el resultado de una apreciación totalmente casuista y subjetiva; y en el momento en que ocurren los eventos, no tienen manera de saber quien será el tribunal arbitral ni su perfil.

Lo anterior no sólo en cuanto al contenido del estándar, sino también en cuanto al método de llegar al mismo y su aplicación.

Lo anterior genera la siguiente interrogante: ¿qué hacer? ¿Es esta diferencia en antecedentes y métodos legales una razón lo suficientemente buena como para desechar todo el mecanismo de arbitraje de inversión?

Considero que no. El sostener que dicha diferencia es suficiente para deshacerse de la institución sería una postura localista y reprobable. Implicaría que problemas de tipo Torre de Babel son insuperables, cuando en verdad no lo son. Crear paredes legales simplemente por la existencia de diferencias culturales o jurídicas nunca es la mejor solución. Las diferencias son mejor apreciadas como oportunidades que como problemas.

Pero es necesario tomar cartas en el asunto. Las diferencias necesitan ser entendidas y utilizadas a favor de la institución. Para ello, considero que existen dos pasos inmediatos y necesarios. Primero, a nivel local: algún tipo de campaña de divulgación y conocimiento del derecho interna- 
cional de la inversión extranjera debe llevarse a cabo para familiarizar a las autoridades locales con dichos estándares. Esto reducirá la división entre las perspectivas locales e internacionales, que en forma creciente merecen menos mérito. En segundo lugar, los tribunales arbitrales deben entender las diferencias e incluirlas en su proceso de toma de decisiones (incluyendo las determinaciones fácticas y la aplicación de derecho) con la finalidad de no apresurarse a encontrar una violación cuando pueda ser que estén en presencia de una diferencia cultural o legal.

En gran medida este segundo paso ya se realiza. Al escoger un árbitro con los antecedentes legales y culturales del Estado huésped, no sólo se filtra el derecho nacional al proceso cognoscitivo del tribunal, sino también el modus operandi local. Visto de esta perspectiva, esto es precisamente lo que hace del arbitraje de inversión la institución mejor equipada para resolver el fenómeno descrito.

\section{RESPUESTAS DE MÉXICO}

La respuesta legal de México a lo anterior ha sido en dos vertientes: 1) La emisión de una nota interpretativa; y 2) Adquirir seguros con empresas especializadas.

\section{Nota interpretativa}

El 31 de julio de 2001 la Comisión de Libre Comercio emitió una nota interpretativa cuya porción relevante al artículo 1105(1) del TLCAN establece que:

B. Estándar Mínimo de Tratamiento de conformidad con el Derecho Internacional

1. El artículo 1105(1) prescribe los estándares mínimos que el derecho consuetudinario internacional establece para el tratamiento de extranjeros como el estándar mínimo que debe ser brindado a las inversiones de inversionistas de otra Parte.

2. Los conceptos de "trato justo y equitativo" y "protección y seguridad plenas" no requieren un tratamiento adicional a, o mejor que, aquél que es requerido por el estándar mínimo contenido en el derecho consuetudinario internacional para el tratamiento de extranjeros. 
3. Una determinación de que ha existido una violación de otra disposición del TLCAN, o de un acuerdo internacional independiente, no implica que haya existido una violación del artículo 1105(1). ${ }^{27}$

Como puede observarse, la nota busca clarificar que el ámbito de protección otorgado de conformidad con el artículo 1105 no es adicional a los umbrales ya existentes de protección bajo el derecho internacional. A su vez, busca evitar una determinación mecánica de una violación al artículo 1105(1) en base a una determinación de violación de otros deberes.

Hay algunos que han sostenido que el artículo 1105 tiene que interpretarse como una capa adicional de protección a los estándares ya existentes de protección, o que incrementaban el nivel de protección mediante la reducción del umbral a partir del cual se generaría responsabilidad. Otros argumentaban que la disposición simplemente busca reflejar la protección existente a la fecha bajo derecho internacional. La clarificación contenida en la nota pone fin al debate.

Hay quien ha cuestionado lo adecuado de dicha nota interpretativa sosteniendo que es una clarificación ex post facto que busca servir a los intereses de los Estados que la emiten en detrimento de los inversionistas. Sin embargo, en la medida en que el artículo 1131 del TLCAN especificamente establece dicha posibilidad, el debate parece carente de sustancia. A su vez, además de su posibilidad legal, existen dos razones por las que considero que el mecanismo sirve un propósito positivo. Por principio de cuentas, el arbitraje de inversión es un mecanismo políticamente delicado que aplica estándares abstractos. Por ello, la posibilidad existe que un tribunal pueda adoptar una interpretación que (a los ojos del Estados huésped) se salga del margen originalmente contemplado y comprometa el deseo de los Estados huésped de continuar obligados a dichos estándares. El artículo 1131 establece una herramienta útil para corregir esta posibilidad, lo cual evita tener que cuestionar a la institu-

27 El texto anterior es una traducción del autor. La versión original en inglés establece que: "B. Minimum Standard of Treatment in Accordance with International Law1. Article 1105(1) prescribes the customary international law minimum standard of treatment of aliens as the minimum standard of treatment to be afforded to investments of investors of another Party. 2. The concepts of "fair and equitable treatment" and "full protection and security" do not require treatment in addition to or beyond that which is required by the customary international law minimum standard of treatment of aliens. 3. A determination that there has been a breach of another provision of the NAFTA, or of a separate international agreement, does not establish that there has been a breach of Article 1105(1)". 
ción de los tratados de inversión y el mecanismo de arbitraje contenido en los mismos. En segundo lugar, si bien en diferentes grados, los tres miembros del TLCAN son economías tanto importadoras como exportadoras de capital. Por consiguiente, tienen un interés en no ser demasiado restrictivos ni liberales en sus interpretaciones vinculativas. Esta situación funciona como un mecanismo auto-equilibrante lo cual evita que se "interprete" de tal manera que opere como una derogación.

\section{Seguro}

El "riesgo" generado por la posibilidad de que inversionistas extranjeros tengan acceso al arbitraje de inversión puede ser abordado de la misma manera que otros riesgos: asegurándose en contra del mismo. Existen dos instrumentos tradicionales: A. El Overseas Private Investment Corporation; y B. El Multilateral Investment Guarantee Agency. A continuación comentaré cada uno.

\section{A. $O P I C$}

El Overseas Private Investment Corporation es una agencia del gobierno de los Estados Unidos de América, cuyo propósito es la promoción de inversiones de estadounidenses inversionistas en otros países (nuevos y en vías de desarrollo). OPIC ofrece dos programas principales: (i) garantías para financiamiento directo y proyectos de inversión; y (ii) seguros contra riesgos no comerciales. Al valorar si se debe apoyar un proyecto, OPIC analiza la contribución del proyecto al desarrollo económico.

\section{B. MIGA}

La Multilateral Investment Guarantee Agency es una organización internacional que forma parte del Grupo del Banco Mundial. Su propósito es la promoción de inversión extranjera directa mediante el otorgamiento de seguros a inversionistas o acreditantes contra riesgo político en sus proyectos con economías emergentes. Estas garantías funcionan como paraguas de protección al disuadir — dado el status de MIGA como parte del Grupo del Banco Mundial- que la conducta gubernamental que pueda interferir en las inversiones, otorgando el posicionamiento necesario para influir positivamente en la resolución de controversias sobre proyectos de inversión, lo cual redunda en beneficio de las 
posibilidades de inversión mediante el incremento de la confianza de inversionistas en la jurisdicción en cuestión.

Los riesgos políticos cubiertos oscilan entre expropiaciones, restricciones a la inconvertibilidad o transferencia de moneda, disturbios civiles, guerras y violaciones contractuales.

De los anteriores, México ha contratado con $\mathrm{OPIC}^{28}$ y está en vías de valorar el hacerse miembro del MIGA. Dado que OPIC está restringido a inversiones de EUA, la membresía con MIGA parece apropiado con la finalidad de abarcar inversiones distintas a las provenientes de EUA.

La adhesión a las instituciones anteriores es un paso positivo. En un principio, la respuesta al arbitraje de inversión era crítica. Aparentemente, la aproximación ha sido refinada, y, en mi opinión, debe ser aplaudida. Ya sea que el arbitraje de inversión persevere-lo cual considero que sucederá - o no, quejarse sobre los casos perdidos es destructivo y no lleva a nada.

El cambio de estrategia ha incluido otros pasos que indican que México ha tomado muy en serio el arbitraje de inversión. Ha ratificado (y continúa negociando) en exceso de 30 tratados de inversión que incluyen arbitraje (ya sea tratados de promoción y protección de inversión o tratados de libre comercio) y ha atacado los casos de los que ha sido parte con un equipo complejo y bien-asesorado de abogados con un entrenamiento internacional, así como asesores externos que constituyen la crema y nata de la materia. El mensaje es claro: México ha honrado sus promesas realizadas mediante tratados de inversión.

Pero no todo merece aplauso. Algunos otros pasos deben tomarse. Considero que dos son indispensables: ratificar el convenio que establece el Centro Internacional para el Arreglo de Diferencias en Materia de Inversión (“CIADI"), y realizar un programa de publicidad y conocimiento sobre el derecho internacional de las inversiones extranjeras (incluyendo los tratados de inversión) y sus estándares. De otra manera, las experiencias de Metalclad, Feldman y Tecmed se repetirán.

28 Firmado ad referéndum el 9 de junio de 2003 y publicado en el Diario Oficial de la Federación el 14 de junio de 2004. 


\section{COMENTARIO FINAL}

No obstante que podría considerarse que de la "medalla" que he otorgado a México - como una de las fuentes de conocimiento y experiencia sobre arbitraje de inversión-es de mérito cuestionable (por no decir lamentable), desde hace tiempo he simpatizado con las palabras de Albert Camus "quiero a mi país demasiado como para ser nacionalista". En forma relacionada, Albert Einstein calificaba al nacionalismo como el sarampión de la humanidad.

El arbitraje de inversión ha evocado argumentos nacionalistas desde varios frentes. Algunos son claramente absurdos-y por ende auto-destructivos - mientras que otros, no obstante que no son evidentemente absurdos, una vez puestos bajo el microscopio, se percibe que carecen de sustancia. Pero una constante es observable: el arbitraje de inversión ha funcionado y parece carecer de alternativas. Por ello, abrazar el mismo, planchando las arrugas que puedan detectarse, es una estrategia sabia. En este sentido, México está liderando el camino. 